\title{
Utilizing Bicycle Compatibility Index and Bicycle Level of Service for Cycleway networks
}

\author{
Qiang Liu ${ }^{1}$, Riken Homma ${ }^{1}$ and Kazuhisa Iki $^{1}$ \\ ${ }^{1}$ Graduate School of Science and Technology, Kumamoto University, Japan
}

\begin{abstract}
Bicycle is widely used in Japan by people of all age groups in daily usage, which may significantly ease traffic congestion. Responding to the cyclists increasing, the method to assess the quality of bicycle travel become necessary. Previous studies reported several approaches to obtain evaluation methods. However, cycleway evaluation in Japan is still far behind the evaluation methods developed in Europe or America. This paper concentrated on familiarizing readers with two methods for evaluating the quality of bicycle facilities and then presenting some proposals of cycleway evaluation in Japan referencing to these two methods. The first method, Bicycle Compatibility Index $(\mathrm{BCI})$, is used to evaluate the road environment for cycling according to the road characteristics by statistical analysis. The second method, Bicycle Level of Service (BLOS), also represents an evaluation of safety for bicyclists. Both of the above methods offered equations of comfort and safety perceptions of bicyclists according to cycling environments. By introducing these methods in combination, this paper enables the readers to maximize the comparative advantages of both $\mathrm{BCI}$ and BLOS. The comparison includes sensitivity of variables and the development of both methods. Then we applied BCI and BLOS to evaluate the target roadways in Kumamoto, Japan.
\end{abstract}

\section{Introduction}

The use of bicycles is increasing and is being promoted as a low cost, healthy, efficient, and non-polluting way of transportation for all age groups. Responding to the increase in the number of cyclists, the bicycle is now considered as an important mode of urban transportation in Japan. To create a more comfortable cycling environment for cyclists, the Japanese government elaborated the Cycleway Improvement Plan to improve the cycleway network. In response to this situation, the method to assess the quality of bicycle travel become necessary. However, there was no methodology widely accepted by engineers and planners to evaluate the environment of the cycleway in Japan. As yet, several researchers from Europe and America have proposed several approaches to obtain evaluation methods. However, the road geometry in Japan is a little different from that in Europe and America. The objective of this research is to familiarize readers with two popular methods for evaluating the quality of bicycle facilities and then compared these two methods. At last, we will present some proposals of cycleway evaluation in Japan referencing to these two methods.

Previous studies reported several approaches to obtain evaluation methods for bicycle. In the 1960s, the Highway Capacity Manual (HCM) presented the level of service (LOS) to assess the roadway of motorized vehicles [1]. In 1997, on the base of LOS, Landis and his team proposed the method of bicycle level of service (BLOS) to assess the perception of safety and comfort in bicycle facilities [2]. The Florida Department of Transportation (FDOT) concluded that the BLOS is the best method. It has been applied to the roadways in America and Canada. In 2007, also based on the LOS, Søren developed a rigorous methodology that can describe the bicyclist level of service in Denmark [3]. For the bicycle compatibility index (BCI), in 1998, it was developed by the Federal Highway Administration (FHWA) in America; it was developed for urban and suburban areas to measure the cycling environment of the roadway segments [4]. The BCI can clearly reflect the impact on bicycle friendliness by traffic and roadway factors such as curb lane width, number of curb lanes, bike lane width, traffic volume, traffic speed and type of roadside development. In 2003, Jones developed a rural bicycle compatibility index (RBCI) for rating of rural roadway segments [5]. And Based on BCI, Ilie present a model to evaluate the gaps in bicycle network designed for India [6]. In Japan, some previous studies have also been working on the evaluation methods for bicycle and BCI was also used in Tokyo to measure the comfort of cyclists. $[7,8]$. However, there was still no method widely accepted in Japan. Planners and engineers in Japan urgently need efficient methods to evaluate the cycleway.

In this paper, it begins by introducing BCI and BLOS respectively to familiarizing readers with them. Next, we compared BCI and BLOS in some aspects so that we can 
enable the readers to maximize the comparative advantages of these two methods. Then we applied BCI and BLOS to evaluate the target roadways in Kumamoto, Japan. According to the results obtained, vehicle volume, curb lane width, and pavement condition of a street segment approach have the most significant influences on its service quality. Finally, some proposals of cycleway evaluation in Japan are presented referencing to comparison of BCI and BLOS.

\section{Bicycle Compatibility Index}

The comfort of cyclists is one of the most common measures used to assess the cycleway environment. In 2005, Hasan used the BCI to generate the most comfortable bicycle routes and, based on the BCI score, a color-coded map was elaborated [9]. In this study, based on the roadway and traffic factors, we used the calculation of BCI to evaluate the cyclists' comfort on each street segment. The comfort index in BCI aims to capture the sentiments of more than 200 participants by letting them watch videos in which the road can be clearly seen. Then, the FHWA let them assess the "bicycle friendliness" of these videos (road segments) according to the cycling environments and through a regression analysis obtained the equation below [10].

$\mathrm{BCI}=3.67-0.966 \mathrm{BL}-0.41 \mathrm{BLW}-0.498 \mathrm{CLW}+0.002 \mathrm{CLV}+$ $0.0004 \mathrm{OLV}+0.022 \mathrm{SPD}+0.506 \mathrm{PKG}-0.264 \mathrm{AREA}+\mathrm{AF}(1)$

where:

$\mathrm{BL}$ : presence of a bicycle lane or paved shoulder $\geq 0.9 \mathrm{~m}$

YES: $\mathrm{BL}=1$; $\mathrm{NO}: \mathrm{BL}=0$;

BLW: bicycle lane (or paved shoulder) width;

CLW: curb lane width;

CLV: curb lane volume;

OLV: other lane(s) volume;

SPD: legal speed limit $+15 \mathrm{~km} / \mathrm{h}$;

PKG: presence of a parking lane with more than $30 \%$ occupancy $\quad$ YES: $\mathrm{PKG}=1$; $\mathrm{NO}: \mathrm{PKG}=0$;

AREA: type of roadside development

Residential: $\mathrm{AREA}=1$; Other type: $\mathrm{AREA}=0$;

AF: $\mathrm{f}_{r}+\mathrm{f}_{u}+\mathrm{f}_{i}, \mathrm{f}_{r}$ : adjustment factor for truck volumes,

$\mathrm{f}_{u}$ : adjustment factor for parking turnover,

$\mathrm{f}_{\mathrm{i}}$ : adjustment factor for right turn volumes.

The concept of compatibility of a roadway with cyclists is an important factor in determining whether the cycleway needs to be improved; thus, we used the BCI to evaluate the compatibility of the roadway environment with cyclists in Kumamoto. The above equation requires various data that would take a lot of times but here we used the data of the traffic census survey (TCS). The TCS website provided the characteristics of the roadways with all the attributes that the BCI needed.

Through equation (1) and the data of TCS, the authors could calculate the compatibility of each of the targeted main road in Kumamoto city. Then we could classify them into several compatibility levels, from high to low level. The compatibility level is also called the BCI level of service (LOS), which is classified into six levels [11]. Different with the LOS defined for motor vehicles, the BCI LOS was developed to describe cyclists [3]. In this study, according to the BCI LOS, the compatibility levels were classified from level $\mathrm{A}$ to level $\mathrm{F}$, as presented in Table 1. The breakpoints between each of the level were defined as the 5 th, 25th, 50th, 75th, and 95th percentiles of the total scores. Level A means that the road segment is extremely comfortable for the cyclist, while level F indicates the worst condition. Poor scores suggest that the roadway segments may need some improvements to enhance the comfort of cyclists. After statistical analysis, using the geographic information system (GIS), we put the calculated results into the map on each segment of the road and the output option is a color-coded map based on the BCI LOS of target roadways in Kumamoto city. Figure 1 shows the BCI results for the target roadways.

Table 1. Bicycle Compatibility Index score.

\begin{tabular}{|c|c|c|}
\hline Level & BCI Range & Compatibility Level \\
\hline A & $0-1.50$ & Extremely High \\
\hline B & $1.51-2.30$ & Very High \\
\hline C & $2.31-3.40$ & Moderately High \\
\hline D & $3.41-4.40$ & Moderately Low \\
\hline E & $4.41-5.30$ & Very Low \\
\hline F & $>5.30$ & Extremely Low \\
\hline
\end{tabular}

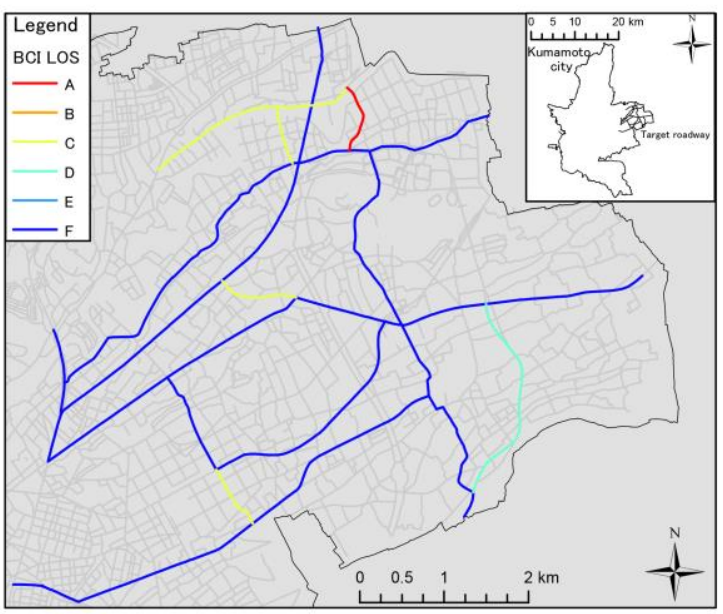

Figure 1. The output option of BCI.

\section{Bicycle Level of Service}

The HCM proposed the concept of BLOS to measure the perception of safety in bicycle facilities. BLOS measures were mainly focused on cyclist comfort on several cycleway facilities but also included some other methods for calculating bicycle delay at intersections. It has been adopted by the FDOT as the recommended standard methodology for cycleway evaluation throughout Florida. An important finding of BLOS was the importance of pavement surface condition which is frequently dismissed by some researchers. In this study, it confirmed that pavement surface condition plays an important role in cycleway evaluation. This method placed 150 participants in actual urban traffic and roadways to obtain feedback on real-time perceptions [2], rather than cyclist 
perceptions to video tapes. According to the perceptions of participants and several relevant variables, the following model was developed through the stepwise regression analysis:

$$
\begin{gathered}
\mathrm{BLOS}=0.507 \ln \left(\mathrm{Vol}_{15} / \mathrm{L}\right)+0.199 \mathrm{SP}_{\mathrm{t}}(1+10.38 \mathrm{HV})^{2}+ \\
7.066\left(1 / \mathrm{PR}_{5}\right)^{2}-0.005 \mathrm{We}^{2}+0.760
\end{gathered}
$$

where:

$\mathrm{Vol}_{15}=$ volume of directional traffic in 15-minute time period;

$\mathrm{L}=$ total number of through lanes;

$\mathrm{SP}_{t}=$ effective speed limit $=1.1199 \ln \left(S P_{p^{-}}-20\right)+0.8103$,

$\mathrm{SP}_{p}$ is posted speed;

$\mathrm{HV}=$ percentage of heavy vehicles;

$\mathrm{PR}_{5}=$ FHWA's 5-point surface condition rating (5=best); $\mathrm{W}_{e}=$ average effective width of outside through lane $=$ $\mathrm{W}_{t}+\mathrm{W}_{l}-\Sigma \mathrm{W}_{r}$,

$\mathrm{W}_{t}=$ total width of outside lane and shoulder/parking pavement,

$\mathrm{W}_{l}=$ width of paving from outside lane stripe to pavement edge,

$\Sigma \mathrm{W}_{r}=$ width reduction due to encroachments in outside lane.

Widespread use of the original form of the BLOS has led to several refinements. In this study, we used Version 2.0 of BLOS model. The same as BCI, equation (2) also need various data and we used the data of TCS to evaluate the compatibility of the roadway environment with cyclists by BLOS. The TCS website provided the characteristics of the roadways with the attributes that the BLOS needed. However, for the Kumamoto city, complete data were not available for all streets. The data were lacking for pavement surface conditions, which were collected in the field and rating by the authors. Table 2 shows the rating example for pavement surface conditions.

Table 2. Pavement condition rating.

\begin{tabular}{|c|c|}
\hline Example & Pavement condition rating \\
\hline$-\ldots$ (very good) \\
\hline
\end{tabular}

Equation (2) produces a BLOS score, which is also stratified into 6 service categories from level A to level F, as presented in Table 3. Level A means that the cyclist is best satisfied for the road segment, while level $\mathrm{F}$ indicates the worst. We used the BLOS calculator (created by League of Illinois Bicyclists) to calculate BLOS score of the roadway segment. The last output option is also a color-coded map based on the BLOS score by using GIS. Figure 2 shows the BLOS results based on BLOS calculator which is the same roadways with BCI.

Table 3. Bicycle Level of Service score.

\begin{tabular}{|c|c|}
\hline Level & BLOS Range \\
\hline A & $0-1.50$ \\
\hline B & $1.51-2.50$ \\
\hline C & $2.51-3.50$ \\
\hline D & $3.51-4.50$ \\
\hline E & $4.51-5.50$ \\
\hline F & $>5.51$ \\
\hline
\end{tabular}

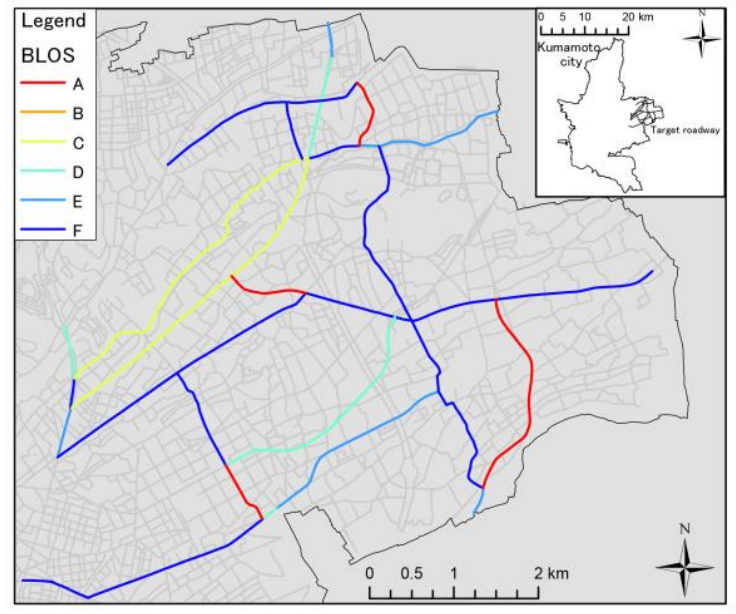

Figure 2. The output option of BLOS

\section{Comparison of $\mathrm{BCl}$ and $\mathrm{BLOS}$}

BCI and BLOS have incorporated the variables that cyclists usually use. Both methods offered equations of comfort and safety perceptions of cyclists according to the roadway environments. Frequently, the results will provide greater detail by using more variables in the equation. However, more variables also let planners and engineers to spend more time and money because of time-consuming data collection. The last output option, color-coded map, can display both BCI and BLOS score of the target roadways and help planners to identify bicycle facilities that may need improvement (the intersections are not taken into consideration). However, there are also some differences between BCI and BLOS. In this section, we compared the basic information about BCI and BLOS which include the organizations, approaches, correlation coefficient $\left(\mathrm{R}^{2}\right)$, variables, etc. Then we described a sensitivity analysis to identify the variables that are sensitive. 


\subsection{The development}

The BCI model has 9 variables (Table 4 ) in the equation with a very high correlation of $\mathrm{R}^{2}=0.89$. BCI was developed by the FHWA based on the research of the Sorton et al. [12] and the Geelong Bikeplan Team [13]. The approaches used to develop BCI model was to get the sentiments of participants by letting them watch videos and then rate the "bicycle friendliness". A Pilot study comparing video survey and field survey was conducted and validated that the video survey is a valid technology to obtain real sentiments from participants. The video survey also can eliminate the risk to participants.

The BLOS was introduced in HCM as a procedure for assessing the comfort of bicycle facilities which include intersections. It has 9 variables (Table 4 ) and the $\mathrm{R}^{2}$ is 0.77 (Version 2.0). The BLOS used a different approach with BCI. Instead of video survey, this method placed participants on actual field to obtain feedback because they considered that video survey cannot include all response stimuli.

Table 4. Variables for $\mathrm{BCI}$ and BLOS

\begin{tabular}{|c|c|c|}
\hline Variable & BCI & BLOS \\
\hline Curb lane width(CLW) & $\mathrm{x}$ & $\mathrm{x}$ \\
\hline Bike lane width(BLW) & $\mathrm{x}$ & $\mathrm{x}$ \\
\hline Paved shoulder width(PSW) & $\mathrm{x}$ & $\mathrm{x}$ \\
\hline Traffic volume(VO) & $\mathrm{x}$ & $\mathrm{x}$ \\
\hline Vehicle speed(VS) & $\mathrm{x}$ & $\mathrm{x}$ \\
\hline Truck volume(TV) & $\mathrm{x}$ & $\mathrm{x}$ \\
\hline On street parking(PARK) & $\mathrm{x}$ & $\mathrm{x}$ \\
\hline Pavement condition(PC) & & $\mathrm{x}$ \\
\hline Lane number(LN) & & $\mathrm{x}$ \\
\hline Roadside development(RD) & $\mathrm{x}$ & \\
\hline Turn right(TR) & $\mathrm{x}$ & \\
\hline
\end{tabular}

Note: An $\mathrm{x}$ indicates the attribute is used for the equation and a blank entry indicates not.

\subsection{Sensitivity analysis}

This section describes the sensitivity analysis for BCI and BLOS. According to the situation of Japan, here we chose 5 key variables to discuss the sensitivity include curb lane width (CLW), paved shoulder width (PSW), traffic volume (VO), vehicle speed (VS), and pavement condition (PC). Using OAT, the most common approach, to change one input variable and then to see what effect on the output. The changed variables and default variables were shown in table 5 . For BCI, other default variables were: paved shoulder width $=$ bike lane width $=1$, truck volume $=80$, on street parking $=0$, lane number $=4$, roadside development $=1$, turn right $=0$. For BLOS, other default variables were: paved shoulder width=bike lane width $=1$, percentage of truck $=2 \%$, on street parking $=0$, lane number $=2$, pavement condition $=4$.
Table 5 compared the sensitivities of BCI and BLOS to change in key variables. Less curb lane width tended to affect BCI by one level (from level D to level C) while extra curb lane width plays a lesser role. However, the BLOS was more sensitive to curb lane width that the level changed from level $D$ to level $B$. The effect of paved shoulder width had less influence on BCI but affected BLOS by one level (from level D to level C). The effect of traffic volume on BCI was changed by four levels, which was more sensitive than BLOS changed by three. Both BCI and BLOS affected by vehicle speed by one level. Poor pavement condition had a significant effect on BLOS that dropped it to the worst category.

Table 5. Sensitivity analysis of BCI and BLOS

\begin{tabular}{|c|c|c|c|c|c|c|}
\hline $\begin{array}{c}\text { CLW } \\
(\mathrm{m})\end{array}$ & $\begin{array}{c}\text { PSW } \\
(\mathrm{m})\end{array}$ & VO & $\begin{array}{c}\mathrm{VS} \\
(\mathrm{km} / \mathrm{h})\end{array}$ & $\mathrm{PC}$ & BCI & BLOS \\
\hline \multicolumn{7}{|c|}{ Default variables } \\
\hline 3.7 & 1 & 4000 & 50 & 4 & 4.68(D) & $3.56(\mathrm{D})$ \\
\hline \multicolumn{7}{|c|}{ Effect of curb lane width } \\
\hline 2.7 & 1 & 4000 & 50 & 4 & $5.18(\mathrm{E})$ & $3.95(\mathrm{D})$ \\
\hline 4.7 & 1 & 4000 & 50 & 4 & 4.18(D) & $3.02(\mathrm{C})$ \\
\hline 5.7 & 1 & 4000 & 50 & 4 & $3.68(\mathrm{D})$ & $2.4(\mathrm{~B})$ \\
\hline \multicolumn{7}{|c|}{ Effect of paved shoulder width } \\
\hline 3.7 & 2 & 4000 & 50 & 4 & $4.27(\mathrm{D})$ & $3.26(\mathrm{C})$ \\
\hline 3.7 & 3 & 4000 & 50 & 4 & $3.86(\mathrm{D})$ & $2.92(\mathrm{C})$ \\
\hline 3.7 & 4 & 4000 & 50 & 4 & $3.45(\mathrm{D})$ & $2.54(\mathrm{C})$ \\
\hline \multicolumn{7}{|c|}{ Effect of traffic volume } \\
\hline 3.7 & 1 & 500 & 50 & 4 & $2.84(\mathrm{C})$ & $2.51(\mathrm{~B})$ \\
\hline 3.7 & 1 & 2000 & 50 & 4 & $3.64(\mathrm{D})$ & $3.21(\mathrm{C})$ \\
\hline 3.7 & 1 & 6000 & 50 & 4 & $5.73(\mathrm{~F})$ & $3.77(\mathrm{D})$ \\
\hline 3.7 & 1 & 8000 & 50 & 4 & $6.78(\mathrm{~F})$ & $3.91(\mathrm{D})$ \\
\hline \multicolumn{7}{|c|}{ Effect of vehicle speed } \\
\hline 3.7 & 1 & 4000 & 30 & 4 & $4.24(\mathrm{D})$ & $3.2(\mathrm{C})$ \\
\hline 3.7 & 1 & 4000 & 40 & 4 & $4.46(\mathrm{D})$ & $3.43(\mathrm{C})$ \\
\hline 3.7 & 1 & 4000 & 60 & 4 & $4.9(\mathrm{E})$ & $3.65(\mathrm{D})$ \\
\hline \multicolumn{7}{|c|}{ Effect of pavement condition } \\
\hline 3.7 & 1 & 4000 & 50 & 1 & - & $10.1(\mathrm{~F})$ \\
\hline 3.7 & 1 & 4000 & 50 & 3 & - & $3.9(\mathrm{D})$ \\
\hline 3.7 & 1 & 4000 & 50 & 5 & - & $3.4(\mathrm{C})$ \\
\hline
\end{tabular}

Note: BCI does not have a pavement condition term.

To identify the importance of variables more intuitively, we used equation (3) to calculate the effect index of each changed key variable to compare with default variables. According to results above, as the effect of paved shoulder width affected both method slightly, we didn 't calculate the effect index. The effect indexes of other variables are shown in table 6.

$$
\mathrm{S}_{i}=\left(\mathrm{V}_{i}-\mathrm{V}_{\text {default }}\right) / \mathrm{V}_{\text {default }}
$$

Where:

$\mathrm{S}_{i}$ : effect index $(\%)$;

$\mathrm{V}_{i}$ : changed BCI/BLOS score;

$\mathrm{V}_{\text {defaul }}$ : default BCI/BLOS score. 
Table 6 compared the effect indexes of BCI and BLOS. Extra curb lane width and less traffic volume strongly decreased the score of BCI and BLOS which means that it can strongly improve the comfort of the roadway segments. However, high traffic volume tended to strongly affect BCI and played less role in BLOS. For the pavement condition, poor conditions had an extremely significant impact on BLOS while good conditions had not. The critical variables can be referenced in the evaluation method in Japan.

Table 6. Variables for BCI and BLOS

\begin{tabular}{|c|c|c||c|c|c|}
\hline $\begin{array}{c}\text { CLW } \\
(\mathrm{m})\end{array}$ & BCI & BLOS & $\begin{array}{c}\text { VS } \\
(\mathrm{km} / \mathrm{h})\end{array}$ & BCI & BLOS \\
\hline 2.7 & $10.6 \%$ & $10.9 \%$ & 30 & $-9.4 \%$ & $-10.1 \%$ \\
\hline 4.7 & $-10.6 \%$ & $-15.1 \%$ & 40 & $-4.7 \%$ & $-3.6 \%$ \\
\hline 5.7 & $-21.3 \%$ & $-32.5 \%$ & 60 & $4.7 \%$ & $2.5 \%$ \\
\hline \hline VO & BCI & BLOS & PC & BCI & BLOS \\
\hline 500 & $-39.3 \%$ & $-29.4 \%$ & 1 & - & $183.7 \%$ \\
\hline 2000 & $-22.2 \%$ & $-9.8 \%$ & 3 & - & $9.5 \%$ \\
\hline 6000 & $22.4 \%$ & $5.8 \%$ & 5 & - & $-4.4 \%$ \\
\hline 8000 & $44.8 \%$ & $9.8 \%$ & & & \\
\hline
\end{tabular}

\section{Conclusions}

This paper introduced two popular methods for evaluating the quality of bicycle facilities and then compared these two methods. BCI and BLOS did the same thing. Both used various characteristics of roadway segments to calculate a BCI/BLOS score of comfort and safety for each roadway segment. After applying BCI and BLOS models in Kumamoto city, the output options indicated that both models are not significantly different.

From both methods we can learn about how to establish the evaluation system in Japan. The designs of BCI and BLOS models research were different. BCI suggested video survey and BLOS suggested field survey. Considering the safety of participants, we suggest that video survey is a better way to be held in Japan. Then we used sensitivity analysis to determine the sensitivity of each variable in BCI and BLOS. The sensitivity analysis exposed that some variables are more critical than other variables in affecting the BCI/BLOS formula. Therefore, the results of sensitivity analysis could help to determine which variables should be referenced in the evaluation method in Japan.

This study enables the readers to maximize the comparative advantages of both BCI and BLOS which will be helpful for researchers in Japan to establish a new evaluation system. It will be helpful not only for the research design but also for the variables chosen. As the results provide greater detail by using more variables. Our future research will continue to find suitable variables by studying on other evaluating methods. However, one challenge we face with is the data availability issue. In addition, although the suitable data may be available, it is only for the main road, not the branch way.

\section{References}

1. Federal Highways Administration (FHWA), Highway Capacity Manual, Washington, D.C., USA (2000).

2. B.W. Landis, V. Vattikuti, , and M. Brannick, Transp. Res. Record, 1578, 119-126 (1997)

3. U.J. Søren, Transp. Res. Record, 2031, 43-51 (2007)

4. Federal Highways Administration (FHWA), Report No. FHWA-RD-98-072. Washington, D.C. (1998).

5. E.G. Jones, T.D. Carlson, Transp. Res. Record 1828 (2003)

6. A. Ilie, C. Oprea, D. Costescu, E. Roşca, O. Dinu, F. Ghionea, IOP Conference Series: Materials science and engineering 161 (2016)

7. S. Takanori, et al, Infrastructure Planning Review of JSCE 47, ROMBUNNO.170 (2013) (in Japanese).

8. H. Nagano, master thesis, Chuo University (2013)

9. Z . Hasan, M. K. Mohammed, Transport, 20, 4, 160164 (2005)

10. D. Harkey, et al, Report No. FHWA-98-072 (1998)

11. Transportation Research Board (TRB), Highway Capacity Manual: Special Report 209, Washington, D.C. (1985)

12. Sorton, Alex and Thomas Walsh, Transp. Res. Record 1438 (1994).

13. Geelong Planning Committee, Geelong Bikeplan Geelong, Australia (1978) 